\title{
Degradation of a Textile Dye C. I. Direct Red 80 by Electrochemical Processes
}

\author{
A. Lopes, " S. Martins, A. Morão, M. Magrinho, I. Gonçalves \\ Department of Chemistry,University of Beira Interior, 6201-001 Covilhã, Portugal
}

Received 16 December 2003; accepted in revised form 21 April 2004

\begin{abstract}
The electrochemical removal of the textile dye C. I. Direct Red 80 (DR80) was carried out using three different materials as anodes: iron, polypyrrole (PPy) and boron doped diamond (BDD). Iron electrodes are consumed during the electrolysis, and promote flocculation/coagulation of the dye. Polypyrrole, a conducting polymer, was prepared by chemical/electrochemical precipitation over a cotton cloth; it enables the precipitation of the dissolved dye through a conversion reaction in a less soluble compound. Boron doped diamond electrode was used to achieve the complete mineralization of the dye. Bulk electrolysis were studied using $\mathrm{Na}_{2} \mathrm{SO}_{4}$ as electrolyte. In the case of the PPy electrode, $\mathrm{NH}_{4} \mathrm{NO}_{3}$ was also used as electrolyte. The variation of the dye concentration was followed by UV-visible absorbance measurements and chemical oxygen demand $(C O D)$ tests were also performed, to compare the rates of colour and $C O D$ removal in each case. From the $C O D$ measurements over the time of electrolysis, using the BDD anode, a mass transfer coefficient for the DR80 molecule was determined. The obtained results show an almost complete colour removal for all the electrodes tested and a COD removal between 50 and $90 \%$, being the best results obtained with the BDD electrode.
\end{abstract}

Keywords: C. I. Direct Red 80, Electrochemical degradation, Diamond electrodes, Polypyrrole electrodes, Dyeing house effluent treatment.

\section{Introduction}

Textile industry involves the use of a multitude of chemical products in the different sub-sectors, leading to a wastewater that is highly variable in pollutant contents. In particular, dyeing processes are responsible for large water

\footnotetext{
* Corresponding author. E-mail address: analopes@ciunix.ubi.pt
} 
consumption and coloured effluents, being aesthetic and with potential toxicity and carcinogenicity. Due to the large amounts of dyeing effluents discharged from dyeing and colouration industries every year, the textile dyeing industry is under considerable pressure to minimize the water consumption and to reduce the colour in effluents discharged to municipal wastewater treatment plants or, in case of on-site treatment plants, in water courses.

Azo dyes are the most important group of the synthetic colourants $(60-70 \%)$ [1]. The azo group $(-\mathrm{N}=\mathrm{N}-)$ characterizes them, in association with aromatic systems and auxochromes (-OH, $-\mathrm{SO}_{3}$, etc.). These groups can be combined in such a diversity of dye molecules that their bio-elimination from effluents becomes a complex matter. Thus, although the biological degradation for organic pollutants is the most economic process, it is not a viable solution for all kind of dyes. In those cases where biological technologies fail, a tertiary treatment has to be performed in order to remove colour and organic load from the effluent. Electrochemical techniques as a tertiary treatment to eliminate colour have been receiving great attention in the last years [2-6]. The application of these methods does not require the use of chemicals, besides a supporting electrolyte, usually already present in the effluents. The only needs are an electric power source and adequate materials to be used as anodes.

Decolourisation can be achieved either by electro-oxidation with non-soluble anodes or by electro-coagulation using consumable materials. The rate of colour and organic load removal depends, among other variables, on the anode's material and the working potential. Several anode materials, with different experimental conditions, have been successfully used in the electro-degradation of hazardous compounds [7-15].

The aim of this work is the study of the electrochemical degradation as a polishing technology of a tetra azo dye, C. I. Direct Red 80 (DR80), using three different anode materials: iron, a conducting polymer (polypyrrole doped with chromium and prepared on a wool textile) and a commercially available boron doped diamond electrode. Sodium sulphate, a salt usually present in the dyeing 
bath, was used as electrolyte. In the case of the polypyrrole electrode, ammonium nitrate was also studied as electrolyte.

\section{Processes occurring at iron electrodes}

The removal of organic compounds from solution using an electrolytic cell with iron electrodes is not yet well understood and it seems to be a combination of several possible mechanisms. According to Lin and Peng [3] the reactions that take place at the electrodes surface are:

$$
\begin{aligned}
& \text { Anode }\left\{\begin{array}{l}
4 \mathrm{Fe} \leftrightarrow 4 \mathrm{Fe}^{2+}+8 \mathrm{e}^{-} \\
4 \mathrm{Fe}^{2+}+10 \mathrm{H}_{2} \mathrm{O}+\mathrm{O}_{2} \leftrightarrow 4 \mathrm{Fe}(\mathrm{OH})_{3}+8 \mathrm{H}^{+}
\end{array}\right. \\
& \text {Cathode } \quad 8 \mathrm{H}^{+}+8 \mathrm{e}^{-} \leftrightarrow 4 \mathrm{H}_{2}
\end{aligned}
$$

Dyes can be eliminated from solution by a combination of the following processes: flocculation/coagulation with ions $\mathrm{Fe}^{3+}$; precipitation with iron hydroxide; reduction to small molecules at the cathode; formation of a competing reaction at the anode [2]

$$
4 \mathrm{Fe}^{2+}+6 \mathrm{H}_{2} \mathrm{O}+\mathrm{O}_{2} \leftrightarrow 4(\mathrm{OH}) \mathrm{OFe}+8 \mathrm{H}^{+}
$$

followed by

$$
\text { Dye- } \mathrm{H}+(\mathrm{OH}) \mathrm{OFe} \rightarrow \text { Dye-OFe }+\mathrm{H}_{2} \mathrm{O}
$$

The precipitated formed is then removed by a sedimentation process.

\section{Processes occurring at polypyrrole electrodes}

Recently, the conducting polymers became an intensive field of research, polypyrrole being one of the most important [16-19]. Its polymerisation can be accomplished by chemical or electrochemical processes. The latter process has the advantage of combining the formation of the polymer and the coat deposition in one single process. Another important characteristic is that it can be 
electrodeposited on substrates as different as textile or stainless steel. Polypyrrole electrodes have been mostly applied as selective electrodes [16, 17], but they can also be used in conversion reactions, especially when the applied potential is lower than the oxygen evolution potential, thus avoiding the occurrence of parallel reactions in a significant extent.

\section{Processes occurring at boron doped diamond electrodes}

Boron doped diamond electrodes are materials suitable to be used as anodes in the electrochemical mineralization of organic compounds. Due to their very high resistance to deactivation via fouling, extreme electrochemical stability, no significant corrosion even under high current densities, good chemical, mechanical and thermal resistance and wide electrochemical potential window in aqueous solutions, they can provide very high current efficiencies [6, 14]. It is widely accepted that the mechanism responsible for the oxidation of organic compounds on these electrodes is an indirect one, being probably mediated by hydroxyl radicals in the region near the electrode $[4,6]$.

According to Panizza et al. [20], the current efficiency is mainly determined by the occurrence of mass transport limitations of the components from the bulk of the solution to the electrode's surface; these are expected to be present in the case of large molecules being processed (due to their low diffusivities) or chemical species in low concentrations. When the electrolysis is carried out under mass transport control, organic compounds are usually completely mineralised, but secondary reactions (oxygen evolution, electrolyte decomposition, etc.) may also take place, resulting in a loss of current efficiency. The rate of oxidation of the organic species can be followed by the rate of $C O D$ decrease, and under diffusive control conditions the following equation may be used [20]:

$$
\frac{\partial C O D}{\partial t}=-\frac{A k_{m} C O D}{V}
$$

where $C O D$ is the chemical oxygen demand $\left(\mathrm{mg}_{\mathrm{O} 2} / \mathrm{L}\right), t$ the time $(\mathrm{s}), A$ the electrode area $\left(\mathrm{m}^{2}\right), V$ the volume of the solution $\left(\mathrm{m}^{3}\right)$ and $k_{m}$ the mass transfer 
coefficient $\left(\mathrm{m} \mathrm{s}^{-1}\right)$. Integration of this equation from $t=0$ and initial $C O D\left(C O D_{i}\right)$ to $t$ and $C O D$ leads to:

$$
C O D=C O D_{i} \exp \left(-\frac{A k_{m}}{V} t\right)
$$

If the applied current density is higher than a certain limit current density, $j_{\text {lim }}$, defined as:

$$
j_{\text {lim }}=(1 / 8) F k_{m} C O D
$$

the electrochemical process is controlled by mass transport, $F$ being the Faraday constant. In this case, the Instantaneous Current Efficiency (ICE) is obtained from:

$$
I C E=\frac{j_{\text {lim }}}{j_{\text {exp }}}
$$

where $j_{\text {exp }}$ is the applied current density. Otherwise, i.e., if the applied current density is lower than the limit one, ICE will be 1.

\section{Experimental}

Electrochemical experiments were conducted at room temperature $\left(\sim 20^{\circ} \mathrm{C}\right)$ in a conventional three-electrode cell. Assays were run using either potentiostatic or galvanostatic modes, using a computer controlled Potentiostat-Galvanostat Tacussel, model PJT 35-2, or an electric power source GW, Laboratory DC Power Supply, Model:GPS-3030D.

The reagent C. I. Direct Red 80 (Fig. 1), P.A., +70\%, was from Ciba Geigy, and used as supplied, without further purification. A stock aqueous solution of 350 mg DR80 / L was prepared in a $5 \mathrm{~g} / \mathrm{L}$ electrolyte solution. The electrolytes tested were: sodium sulphate (Merck, P.A., +99.5\%), and ammonium nitrate (Merck, P.A., $+99 \%)$.

In the $\operatorname{PPy}(\mathrm{Cr}) /$ wool electrode preparation the following reagents were used: pyrrole (Aldrich, P.A., +98 \%), iron chloride (III) hexa-hydrated (Merck, P.A., +99\%), ethanol (Merck, P.A., +96\%), petroleum ether (Merck, 40-60) and chromium chloride (Merck, P.A., +96\%). 


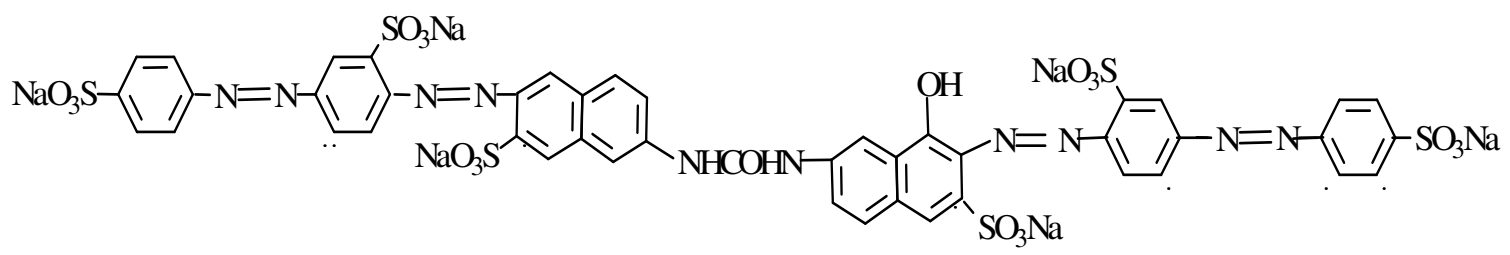

Figure 1. C. I. Direct Red structure.

In the degradation assays using the iron electrode, the electrolyte tested was sodium sulphate and the volume of the solution was $100 \mathrm{~mL}$. The geometric immersed area of the anode was $10 \mathrm{~cm}^{2}$, the anode and the cathode being identical. These experiments were carried out in potentiostatic mode, at 1,2 and $3 \mathrm{~V}$, and galvanostatic mode, at 50 and $100 \mathrm{~mA}$.

The $\operatorname{PPy}(\mathrm{Cr}) /$ wool electrode was prepared as follows: the wool cloth, after carefully washed, was imbibed in a solution containing $5 \%(\mathrm{w} / \mathrm{w})$ ammonium nitrate and $10 \%(\mathrm{w} / \mathrm{w})$ iron chloride (III) and, after that, it was immersed in a mixture of pyrrole/ethanol/petroleum ether in the volumetric ratio of 1/1/4. After solvents evaporation, the textile was submitted to an electrochemical polymerisation in a conventional three-electrode cell, working at $2{ }^{\circ} \mathrm{C}$, with a potential of $+800 \mathrm{mV}$ versus the reference electrode, using as working electrode the imbibed textile, as auxiliary electrode a copper foil and, as reference, a $\mathrm{Ag} / \mathrm{AgCl}$ saturated electrode. As electrolyte, a mixture made of an aqueous solution, saturated with chromium chloride and with $5 \%(\mathrm{w} / \mathrm{w})$ ammonium nitrate, ethanol and pyrrole, in the volumetric ratio 25/2/1, was used. The polymerisation took place for 24 hours. When working as anodes in the degradation assays, the immersed area of $\mathrm{PPy}(\mathrm{Cr}) /$ wool electrodes was $5 \mathrm{~cm}^{2}$. In these experiments, a stainless steel foil with $5 \mathrm{~cm}^{2}$ area was used as cathode. In the assays of the electrochemical degradation of DR80 using Ppy electrodes, two different electrolytes were used: sodium sulphate and ammonium nitrate. These assays were carried out in galvanostatic mode, with an applied current intensity of $2 \mathrm{~mA}$, and the volume of the solution was $100 \mathrm{~mL}$. Two PPy electrodes, prepared simultaneously, were used, one for each electrolyte. 
Between experiments, they were thoroughly washed with deionised water and kept in fresh deionised water for 24 hours.

The boron doped diamond electrode (BDD-DiaChem ${ }^{\circledR}$ ) was kindly supplied by the Centre Suisse d'Electronique et de Microtechnique SA (CSEM). The experiments with this electrode were run in a plug-flow cell, with a geometric area of BDD of $8.4 \mathrm{~cm}^{2}$ and using as cathode a copper foil with identical area. The working mode was the galvanostatic, with an imposed current density of 1.5 and $2.5 \mathrm{~mA} \mathrm{~cm}^{-2}$, for 200 and $300 \mathrm{~mL}$ of solution, respectively. The assays were conducted in a batch system, with re-circulation. A pump, Concessus $2 \mathrm{md}$ little giant, was used to enable the circulation of the solution.

During the degradation tests, dye concentration was determined by spectrophotometry at $540 \mathrm{~nm}$, using a Perkin-Elmer Lambda 6 UV/VIS spectrophotometer. A dye free cell was used as control. Chemical Oxygen Demand determinations were carried out by the standard colorimetric (titrimetric) method [21].

\section{Results and discussion}

The results obtained with the three different electrodes, namely the current intensity for potentiostatic assays or the potential for the galvanostatic experiments, the duration of the essay, the percentages of colour and COD removal, the initial and final $\mathrm{pH}$ and the energy consumption, are presented in Table 1.

\section{Iron electrodes}

The spectra of samples collected at different times, for four runs, are shown in Fig. 2. In plot a) we can simply observe the removal of dye from the solution, that occurs by precipitation, but in plots b) to d), obtained for higher potentials (see Table 1), there is a significant change in the spectra with time, with the appearance of a band at approximately $370 \mathrm{~nm}$. This band, possibly due to the degradation of the dye and the formation of smaller molecules, arises 
simultaneously with the observation of a different colour in solution. When this happens, there is sudden precipitation of a purple compound.

Table 1. Results obtained on the degradation assays performed with three different electrodes: iron, polypyrrole (PPy) and boron doped diamond (BDD).

\begin{tabular}{|c|c|c|c|c|c|c|c|c|}
\hline Electrode & Essay & $\begin{array}{c}\text { Obtained } \\
\mathrm{mA} \text { or } \mathrm{V}(*)\end{array}$ & $\mathrm{t} / \mathrm{h}$ & $\%$ Colour removal & $\begin{array}{l}\% \text { COD } \\
\text { Removal }\end{array}$ & $\mathrm{pH}_{\mathrm{i}}$ & $\mathrm{pH}_{\mathrm{f}}$ & $\begin{array}{l}\text { Energy consumption } \\
\qquad \mathrm{kW} \mathrm{h} \mathrm{m}^{-3}\end{array}$ \\
\hline \multirow{5}{*}{ Iron } & $1.0 \mathrm{~V}$ & $10 \mathrm{~mA}$ & 4 & 83 & 52 & \multirow{5}{*}{6.7} & 7.4 & 0.39 \\
\hline & $2.0 \mathrm{~V}$ & $37 \mathrm{~mA}$ & 1.5 & 97 & 42 & & 8.0 & 1.12 \\
\hline & $3.0 \mathrm{~V}$ & $66 \mathrm{~mA}$ & 1.5 & 99 & 42 & & 10.9 & 2.02 \\
\hline & $5.0 \mathrm{~mA} \mathrm{~cm}^{-2}$ & $2.0 \mathrm{~V}$ & 1.5 & 99 & 49 & & 7.9 & 1.34 \\
\hline & $10.0 \mathrm{~mA} \mathrm{~cm}^{-2}$ & $3.3 \mathrm{~V}$ & 1 & 99 & 46 & & 9.3 & 3.30 \\
\hline \multirow{4}{*}{ PPy } & $\mathrm{Na}_{2} \mathrm{SO}_{4}(1)-2 \mathrm{~mA}$ & $3.5 \mathrm{~V}$ & 93 & 94 & 42 & 6.7 & 8.5 & 6.51 \\
\hline & $\mathrm{Na}_{2} \mathrm{SO}_{4}(2)-2 \mathrm{~mA}$ & $5.0 \mathrm{~V}$ & 96 & 47 & - & \multirow{3}{*}{6.4} & 10.4 & 9.60 \\
\hline & $\mathrm{NH}_{4} \mathrm{NO}_{3}$ (1)- $2 \mathrm{~mA}$ & $3.9 \mathrm{~V}$ & 70 & 100 & 46 & & 7.8 & 5.46 \\
\hline & $\mathrm{NH}_{4} \mathrm{NO}_{3}$ (2)- $2 \mathrm{~mA}$ & $2.8 \mathrm{~V}$ & 96 & 81 & 55 & & 8.3 & 5.30 \\
\hline \multirow{2}{*}{ BDD } & $1.5 \mathrm{~mA} \mathrm{~cm}^{-2}$ & $4.4 \mathrm{~V}$ & 24 & 99 & 87 & \multirow{2}{*}{6.7} & \multirow[b]{2}{*}{4} & 6.65 \\
\hline & $2.5 \mathrm{~mA} \mathrm{~cm}^{-2}$ & $5.0 \mathrm{~V}$ & 42 & 100 & 76 & & & 14.70 \\
\hline
\end{tabular}

(*) average values obtained during the assays ("mA" for potentiostatic runs and "V" for galvanostatic runs).

(1), (2) - first and second assays with the same electrode, respectively.
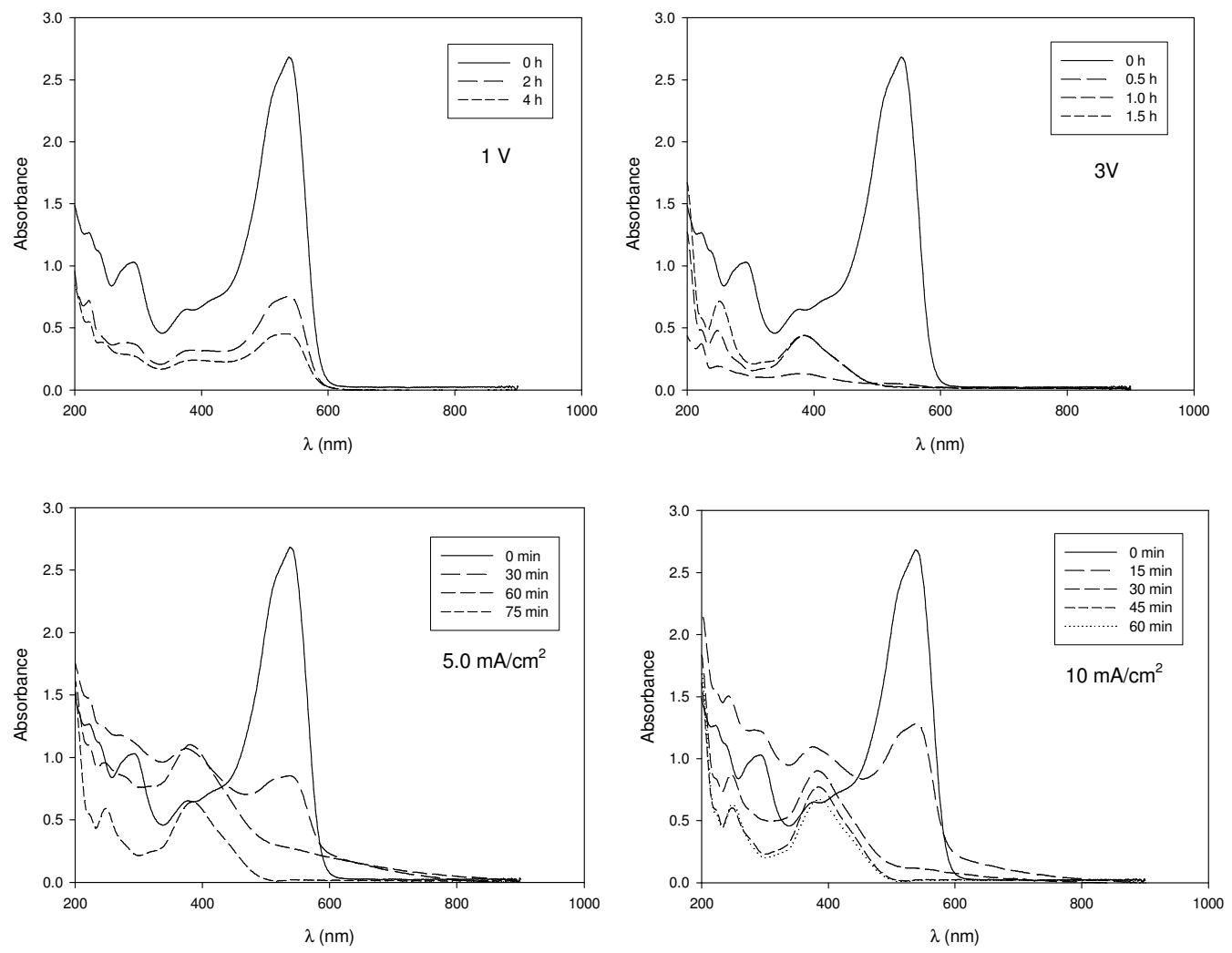

Figure 2. UV-visible spectra for the electrochemical degradation of DR80 using iron electrodes, at different times: a) and b) - potentiostatic mode, with 1 and $3 \mathrm{~V}$ imposed potential, respectively; c) and d) - galvanostatic mode, with 50 and $100 \mathrm{~mA}$ imposed current, respectively. 
The percentages of colour and $C O D$ removal at the end of the assays, as well as the variation of $\mathrm{pH}$, presented in Table 1, show that essay corresponding to Fig. 2 a) presents lower colour removal but higher $C O D$ removal, which suggests the occurrence of simple precipitation without the formation of smaller molecules. The increase in $\mathrm{pH}$ as the voltage or applied current are increased is compatible with the formation of hydroxide ion and hydroxides.

In Fig. 3 the variation of percentage of colour removed versus electricity consumption is presented. Up to a certain level of colour removal, the electrochemical process becomes more expensive as the applied potential or current are increased. Apparently the colour removal is mainly determined by the charge applied to the system up to a certain critical value (c.a. 600 A.h.m ${ }^{-3}$ in this case, see Fig.4).

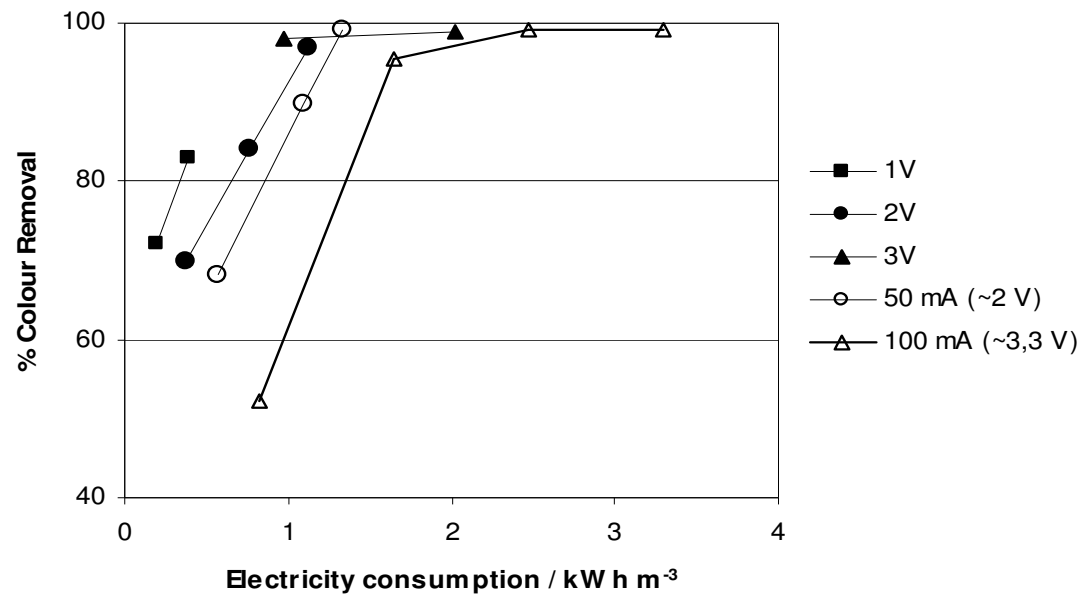

Figure 3. Percentage of colour removal versus electricity consumption in the electrochemical degradation of DR80, using iron electrodes and different experimental conditions.

From data in Table 1, we can see also that colour is always removed faster than $C O D$ and, from the spectra, that at $540 \mathrm{~nm}$ the absorbance decreases faster than at other wavelengths. This strongly suggests the occurrence of cleavage in azo bonds, as these are responsible by the characteristic absorptivity at this particular wavelength. 


\section{Polypyrrole electrode}

The spectra for the experiments performed with the two electrolytes, at different times, are shown in Fig. 5. The spectra for solutions of ammonium nitrate, ammonium and potassium nitrate are also represented in the same figure, in order to identify the bands due to the nitrate ion. It may be concluded that, except for the starting solution of the dye when $\mathrm{Na}_{2} \mathrm{SO}_{4}$ was used as supporting electrolyte, the characteristic bands due to the nitrate ion are always present in the spectra. This fact means that this salt possibly acts as an intermediate in the electrochemical reaction of precipitation of the dye, probably by a reaction with the sulphate groups of the dye that are responsible for its solubility. Like in the tests performed with iron absorbance at $540 \mathrm{~nm}$ also decreases faster than COD. As it can be seen also in Table 1, in these assays, an increase in $\mathrm{pH}$ means a decrease in colour and $C O D$ removal, disagreeing to the observed behaviour with the iron electrodes experiments.

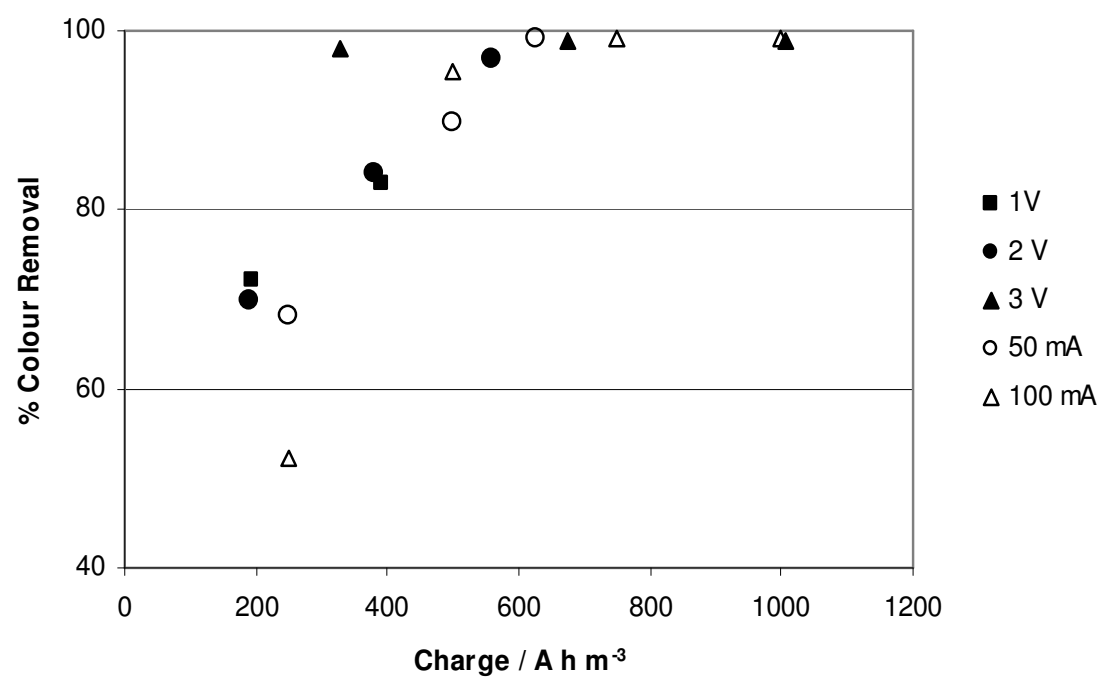

Figure 4. Percentage of colour removal versus charge passed for the electrochemical degradation of DR80, using iron electrodes and different experimental conditions.

In the second experiment with sodium sulphate as electrolyte, there is a decrease in colour removal. This fact is probably associated with the low concentration in 
nitrate ion, since the only possible source is the one incorporated in the electrode during its preparation.
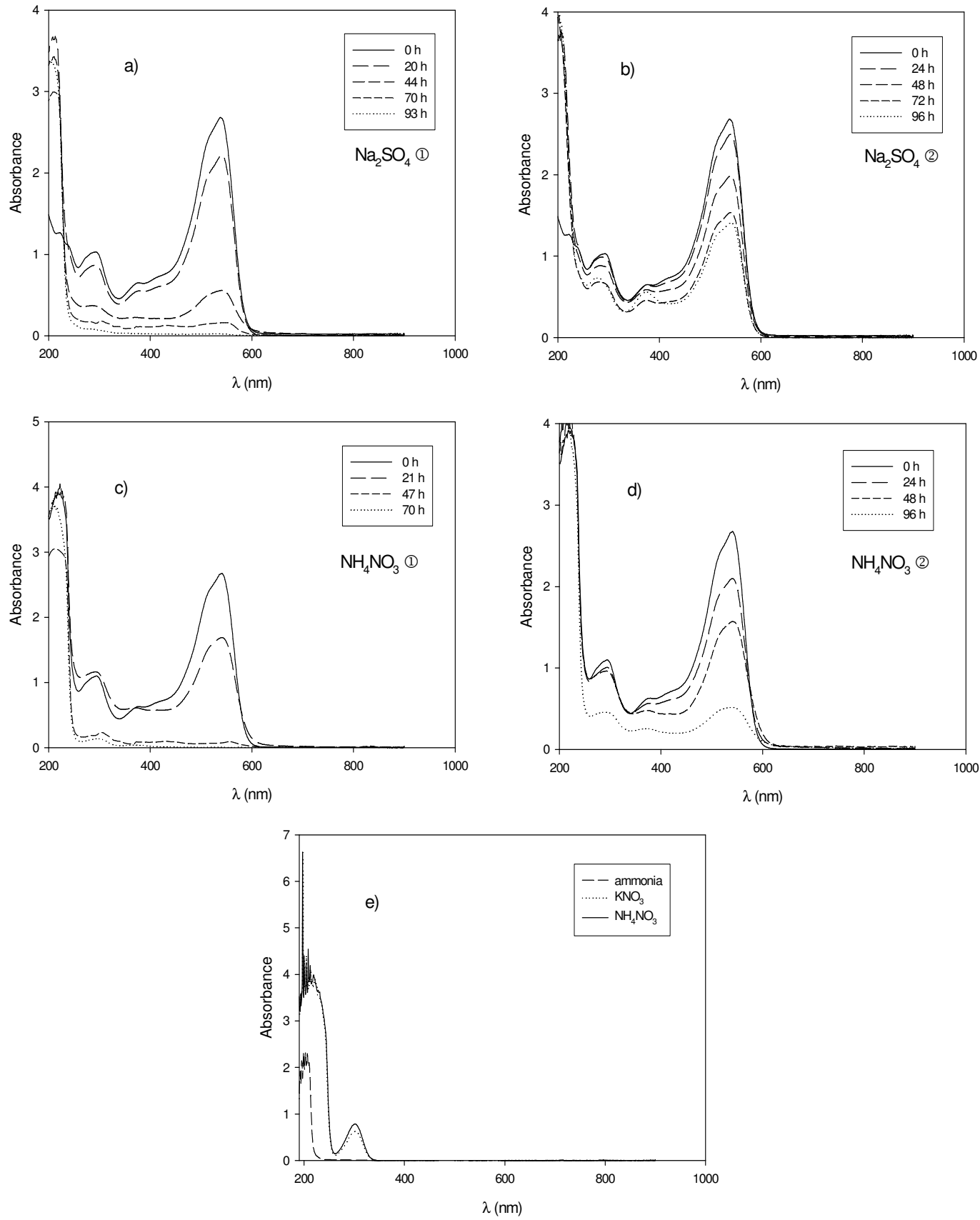

Figure 5. a)-d) UV-visible spectra for the electrochemical degradation of DR80 using PPy electrodes, at different times, for two electrolytes - a) and b) sodium sulphate; c) and d) ammonium nitrate. e) UV-visible spectra for solutions of ammonia, ammonium nitrate and potassium nitrate. 


\section{Boron doped diamond electrode}

The rate of the electrochemical degradation of DR80, besides being followed by UV-visible spectrophotometry (Fig. 6), was also monitored by $C O D$ analysis. In Fig. 7, $\left[\ln \left(C O D / C O D_{\mathrm{i}}\right)(V / A)\right]$ is plotted as a function of time (eq. 2) for the various assays, all carried out under diffusive control, i.e., at current densities higher than the limiting current, $j_{\text {lim }}$. From this plot, an average mass transfer coefficient of $5 \times 10^{-6} \mathrm{~m} \mathrm{~s}^{-1}$, with a standard error of $\pm 5 \times 10^{-7} \mathrm{~m} \mathrm{~s}^{-1}$, was obtained by a linear fitting, passing through the origin of the coordinates.
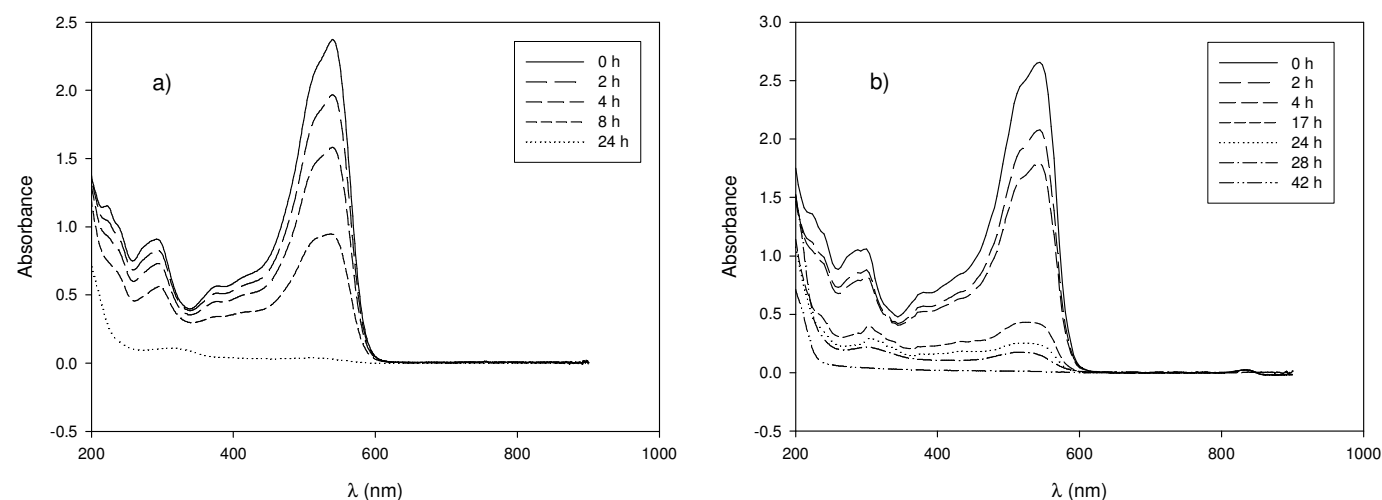

Figure 6. UV-visible spectra for the electrochemical degradation of DR80 using BDD electrodes, at different times: a) current density of $1.5 \mathrm{~mA} \mathrm{~cm}^{-2}$; b) current density of 2.5 $\mathrm{mA} \mathrm{cm}{ }^{-2}$.

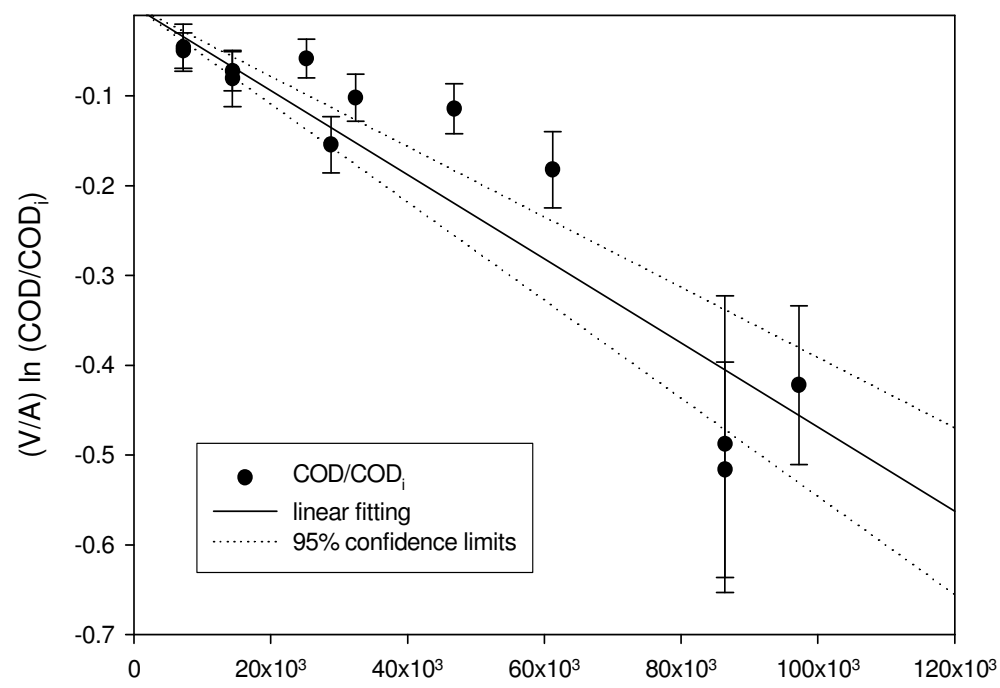

$\mathrm{t}(\mathrm{s})$

Figure 7. Variation of $\left[\ln \left(C O D / C O D_{\mathrm{i}}\right)(V / A)\right]$ with time (eq. 2) for the electrochemical degradation of DR80 performed with BDD electrode. 
If a comparison between percentage of $C O D$ and colour removal is made, as in Fig. 8 (see also Table 1), it can be observed that the difference between the rates of colour and COD removal is smaller for these electrodes than for the other types previously discussed, especially for the lower current density, when current efficiency is higher.

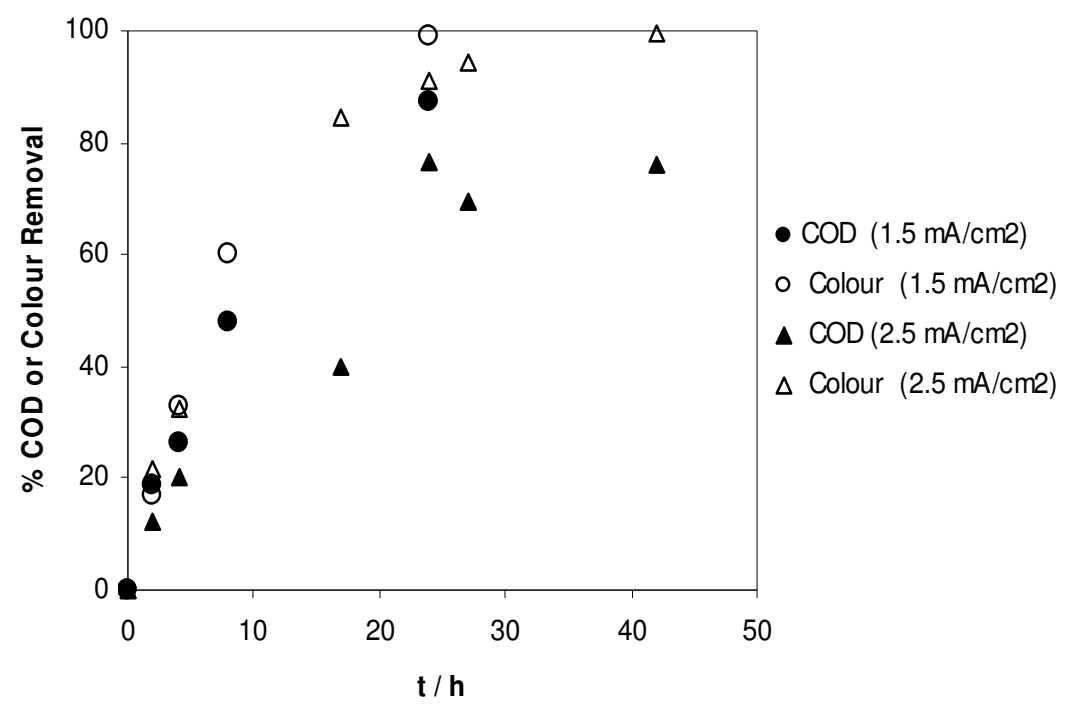

Figure 8. Percentages of colour and $C O D$ removal for the electrochemical degradation of DR80 performed with BDD electrode.

These results were expected since, for this kind of electrodes the accumulation of intermediates is expected to occur only in very low amounts due to the occurrence of fast combustion reactions [13-16]. This is also corroborated by the observation of Fig. 6, where there is no formation of any new absorption bands on the obtained spectra. In fact, although the applied potentials used in these tests were very high, the obtained spectra for BDD are quite similar to those obtained with iron (at $1.0 \mathrm{~V}$ ) and PPy.

\section{Conclusions}

Three different electrodes were used in the electrochemical removal of the dye DR80 from solution: iron, polypyrrole doped with chromium and boron doped 
diamond electrode. The removal of the dye from solution was followed by UVvis spectrophotometry and $C O D$ determinations.

Using iron electrodes, percentages of colour removal between 83 and 99 were obtained, for applied potential of $1 \mathrm{~V}$ and for higher potential than $1 \mathrm{~V}$, respectively. The COD removal was about $50 \%$, being the higher value obtained for the essay with lower colour removal, suggesting that at higher potentials other molecules with higher solubility may be formed.

The PPy electrodes, doped with chromium and prepared over a wool substrate, were used with two different electrolytes: sodium sulphate and ammonium nitrate. An almost complete colour removal was obtained with ammonium nitrate that seems to be involved in the mechanism of the precipitation of the dye. With sodium sulphate the results were not so good, especially when the electrode was used for the second time.

The electrochemical method, using a BDD anode, has been employed in the present study to mineralize the dye.

Almost complete colour and $C O D$ removals were attained using this technique, applying high potentials and current densities. From the assays carried out in diffusive control, an average mass transfer coefficient was obtained for the dye. The obtained UV-visible spectra are very similar to those found for iron and PPy, but the current densities applied on BDD electrodes were considerably high. Thus, since the percentage of colour removal seems to depend essentially on the applied charge, a choice between iron (or PPy) electrodes of large areas and BDD electrodes with smaller ones should be considered for practical applications.

\section{Acknowledgements}

The financial support of Fundação para a Ciência e a Tecnologia (FCT), POCTI/EQ/32456/1999 and SFRH/BD/6485/2001, as well as the Centre Suisse d'Electronique et de Microtechnique SA (CSEM), are gratefully acknowledged. 


\section{References}

1. I.G. Laing, Rev. Prog. Coloration 21 (1991) 56.

2. A. Wilcock, M. Brewster, W. Tincher, American Dyestuff Reporter, August (1992) 15.

3. S.H. Lin, C.F. Peng, Water Research 28(2) (1994) 277.

4. M.C. Gutiérrez, M. Crespi, J. Soc. Dyers Colourists 115 (1999) 342.

5. J.P. Lorimer, T.J. Mason, M. Plattes, S.S. Phull, D.J. Walton, Pure and Applied Chemistry 73(12) (2001) 1957.

6. A. Morão, A. Lopes, M.T. Pessoa de Amorim, I.C. Gonçalves, Electrochimica Acta 49 (9-10) (2004) 1587.

7. C. Comninellis, C. Pulgarin, J. Applied Electrochemistry 21 (1993) 703.

8. K. Tennakone, C.T.K. Tilakaratne, I.R.M. Kottegoda, J. Photochemistry and Photobiology 87 (1995) 177.

9. $\quad$ S. Zor, B. Yazici, M. Erbil, H. Galip, Water Research 32(3) (1998) 579.

10. E. Brillas, E. Mur, R. Sauleda, L. Sànchez, J. Peral, X. Domènech, J. Casado, J. Advanced Oxidation Technology 4(1) (1999) 109.

11. D.C. Johnson, J. Feng, L.L. Houk, Electrochimica Acta 46 (2000) 323-330.

12. M. Hepel, J. Luo, Electrochimica Acta 47 (2001) 729.

13. J. Iniesta, A. Michaud, M. Panniza, C. Comninellis, Electrochemistry Communications 3 (2001) 346.

14. M. Fryda, D. Herrmann, L. Schäfer, C.P. Klages, A. Perret, W. Haenni, C. Comninellis, D. Gandini, New Diamond and Frontier Carbon Technology 9(3) (1999) 229.

15. A. Fernandes, A. Morão, M. Magrinho, A. Lopes, I. Gonçalves, Dyes and Pigments 61(3) (2004) 287.

16. H. Kaden, H. Jahn, M. Berthold, K. Jüttner, K.M. Mangold, S. Schäfer, Chem. Eng. Technol. 24 (2001) 1120.

17. A. Ersöz, V. Gavalas, L. Bachas, Anal. Bioanal. Chem. 372 (2002) 786.

18. A. Fenelon, C. Breslin, Electrochimica Acta 47 (2002) 4467.

19. A.C. Cascalheira, S. Aeiyach, P.C. Lacaze, M.L. Abrantes, Electrochimica Acta 48 (2003) 2523. 
20. M. Pannizza, P.A. Michaud, G. Cerisola, C. Comninellis, J. Electroanalytical Chemistry 507 (2001) 206.

21. A. Eaton, L. Clesceri, A. Greenberg, Standard Methods for Examination of Water and Wastewater, 19 th Edition, 1995. 